\section{Australian Journal of \\ Crop Science}

\title{
Assessment of diversity and population structure of mango (Mangifera indica L.) germplasm based on microsatellite (SSR) markers
}

\author{
Shahril Ab Razak ${ }^{1 *}$, Nor Helwa Ezzah Nor Azman ${ }^{1}$, Siti Norhayati Ismail ${ }^{1}$, Muhammad Fairuz Mohd Yusof ${ }^{1}$, \\ Muhammad Afiq Tajol Ariffin ${ }^{2}$, Zul Helmey Mohamad Sabdin ${ }^{3}$, Muhamad Hafiz Muhamad Hassan', \\ Khairun Hisam Nasir ${ }^{1}$, Mohd Asrul Sani ${ }^{4}$, Norzihan Abdullah ${ }^{1}$
}

\author{
${ }^{1}$ Centre for Marker Discovery and Validation (CMDV), MARDI Headquarters, Selangor, Malaysia \\ ${ }^{2}$ Horticulture Research Centre, MARDI Sintok, Kedah, Malaysia \\ ${ }^{3}$ Seed and Gene Bank Centre, MARDI Sintok, Kedah, Malaysia \\ ${ }^{4}$ Director General Office, MARDI Alor Setar, Kedah, Malaysia
}

*Corresponding author: shahrilf@mardi.gov.my

\begin{abstract}
The assessment of genetic diversity is essential for the conservation and breeding purposes. This study aimed to assess and evaluate the genetic diversity of 116 accessions of mango (Mangifera indica) germplasm using microsatellite markers. The DNA was extracted from young fresh leaf before genotyping using microsatellites to determine the allele size. The analysis of 20 polymorphic microsatellite markers revealed a total of 122 alleles ranging from two (MillHR10, MillHR21, and MillHR25) to 11 alleles per locus (MillHR28 and MillHR30) with an average of 6.1. The mean polymorphic information content (PIC) value was 0.4585 which ranged between 0.0081 (MillHR10) to 0.9573 (MillHR28). The UPGMA dendrogram indicated that the accessions were divided into two major clusters, which were divided into several sub-clusters based on their genetic distance matrix values. Some accessions were highly similar to each other, probably due to the duplication of collected accessions or insufficient microsatellite markers to differentiate them. The analysis of the population structure of the individuals also showed two subpopulations, suggesting that the accessions could be separated into two groups, which supported the generated dendrogram. The findings of this study facilitate improved conservation management of the germplasm and help to find strategies for future breeding activities.
\end{abstract}

Keywords: Genetic variation, SSR marker, Mango Germplasm

Introduction

Mangifera indica Linn., popularly referred to as mango, is one of the most popular fruit crops in the tropical and subtropical regions of the world (Khan et al., 2015). M. indica $(2 n=40)$ is one of roughly 850 species which are grouped into 73 genera in the family of Anacardiaceae under the order Sapindales. The genus Mangifera consists of about 70 species distributed in tropical Asia and can be separated into two sub-genera (Limus and Mangifera), wherein mango is classified in the sub-genus Mangifera (Shamili et al., 2012). It is considered to be one of the most economically important food crops, cultivated mainly for either industrial consumption or just to be eaten as a fruit. Mangoes have pan-tropical distribution owing to extensive cultivation and naturalization through several centuries and also because they are highly adaptive. It is considered to be a native fruitcrop originating from the Indian sub-continent and Southern Asia, where it originated as an allopolyploid. Either way, the practice of mango cultivation most likely originated from India, where there is over 1000 different known varieties, most of which occur naturally from open-pollinated seedlings (Shamili et al., 2012; Iyer and Degani, 1997). Domestication of mango began more than 400 years ago. The subsequent migration of human populations resulted in the outward spread and naturalization of mangoes to Southeast Asia, then to Africa, Central America, and finally South America. Presently, more than 90 countries are producing mangoes, but only a small proportion of this produce makes it to the international trading channels. However, the past two decades have witnessed a considerable increase in the traded volume (Evan and Mendoza, 2009). Mangoes are considered to be one of the most popular and valued fruit crops and account for almost $50 \%$ of the global tropical fruit production, which equates to $5.5 \%$ of the total annual fruit production globally. According to Shamili et al. (2012) based on Food and Agriculture Organization (FAO) statistic in 2010, the global mango production reached about 40 million tons, placing mango among the top five most important fruit crops worldwide. India, China, Thailand, Mexico, Pakistan, and Indonesia produce over $75 \%$ of all the mangoes, of which India is the main producer with over 15 million tons produced $(40 \%$ of the global production).

Exploitation of germplasms with distinguishing characteristics in breeding programs needs exact information in order to develop new cultivars. Different mango cultivars globally have several limitations such as low 
production, alternate bearing, narrow ripening time frame, and low quality of fruits. Therefore, it is critical to rectify the genetic disparity in mango and conserve the threatened and commercial mango cultivars to extend and expand the genetic resources (Litz, 2004). The expansion of agricultural activity has led to mango plantations, either commercial or wild, to be disturbed and destroyed. This has caused irreversible depletion of the genetic resources of mango. Therefore, it is essential to formulate long-term plans in order to safeguard and conserve the genetic resources of mango. This can be done by implementing both in situ and ex-situ conservation approaches (Bompard, 1993). Conservation of genetic resources of mango requires the identification, characterization, and assessment of the genotypes for effective utilization in mango breeding programs and appropriate conservation management (Khan et al., 2015). Several methods and approaches, including morphological, biochemical, and molecular or DNA markerbased characterization and identification of mango genotypes have been applied globally. Markers can easily identify features specific to plants, which can be recorded with confidence and are comparatively abundant. In general, there are two main types of genotypic markers: molecular markers and morphological markers. Conventional characterization of mango cultivars was based on the morphological characters of the flowers, leaves, fruits, and seeds (Bhat et al., 2010). Although the use of morphological traits for the characterization of cultivars is still important for proper identification genotypes, the sole use of morphological traits often leads to inaccurate and inconsistent results, owing to the environmental influence and phenological factors, which is often restricted by the number of distinct contrasting characters (Khan et al., 2015). Therefore, molecular markers provide a more dependable alternative to morphological markers. Similar to other fruit species, molecular-based identification of mango cultivars has recently been done using various molecular marker systems such as isozymes, ISSRs, AFLPs, RAPDs, SCOTS, microsatellites or SSRs (Majumder et al., 2012; Pruthvish and Chikkaswamy, 2016; Luo et al., 2011; Shamili et al., 2012), and even more recently, Single Nucleotide Polymorphism (SNP) (Sherman et al., 2015). High throughput microsatellite markers are extremely sensitive and extensively used in plant genomic studies because of their highly polymorphic, abundant, multi-allelic nature, simple analytical procedure and transferability across genotypes (Vieira et al., 2016). Therefore, they are beneficial to increase the efficiency of classification and identification of mango accessions, giving necessary information for future biodiversity conservation and gene bank management. Also the availability of published or reported SSR markers of Mangifera indica has brought us to assess the genetic diversity of our mango germplasm.

\section{Results}

\section{Characterization of microsatellite markers}

A total of 32 microsatellite markers were initially used to evaluate the mango germplasm containing 116 mango accessions. Only $20(62.5 \%)$ microsatellite markers were polymorphic and amplifiable across the accessions. The remaining microsatellite markers were discarded because they were either monomorphic or failed to amplify for more than $90 \%$ of the total number of accession. The analysis of the selected 20 microsatellite markers revealed a total of 122 alleles with an average of 6.1 alleles per locus and range from two (MillHR10, MillHR21, and MillHR25) to 11 (MillHR28 and MillHR30). Both microsatellite markers (MillHR28 and MillHR30) that showed the presence of the highest number of alleles were simple di-repeat motif SSR markers. The PIC ranged from 0.0081 (MillHR10) to 0.9573 (MillHR28) with an average of 0.4585 . The PIC value was used to assess the informativeness of the molecular markers used in this study. Following the philosophy of Hildebrand et al. (1994), only five microsatellite markers (25\%) were considered to be highly informative (PIC value $>0.7$ ). In addition, the value of heterozygosity per locus ranged from 0.000 (MillHR10) to 0.8443 (MillHR29). The details of the characterization of the 20 polymorphic SSR markers are summarized in Table 1.

\section{Genetic diversity and population structure of selected mango germplasm}

The UPGMA dendrogram (Figure 1), generated from shared allele matrix, indicated that the studied germplasm was divided into two major clusters (Green and Red cluster). Green cluster consisted of 37 (31.9\%) accessions, while the remaining accessions (68.1\%) were grouped in Red Cluster. Within these two major clusters, there were several subclusters based on the values of genetic distance matrices. The dendrogram also revealed high similarity between certain accession within their sub-clusters (Group 1: Harumanis, MLooi, Gadung, and Graham; Group 2: Berselera and Haji Yusuf; Group 3: Bobby, Ind_Mayu, Telor, Sri Siam, IR Taiwan, and Serdang; Group 4: Tony_B, Tony_C, MARDI_1, and MARDI_6), which might be caused either by duplication in accession collection or insufficiency of microsatellite markers to differentiate the varieties. The pairwise genetic distance showed the highest genetic distance (0.7941) between Tetenene and Bangkok2, and between Tetenene and Okrong (Supplementary Table 3).

A plot of $\Delta K$ against the number of $K$ as described by Evanno et al. (2005) showed that the optimal $\Delta K$ was at $K=2$ (Figure 2). This suggested that the population structure of the 224 plant individuals consisted of two genetically distinct genotype groups. These analyses supported the dendrogram analysis, which also revealed the presence of two major clusters. Both clusters showed a mixture of poly-embryonic and mono-embryonic seed-type varieties in their cluster.

\section{Discussion}

SSRs remain the most trusted markers for genotyping plants for more than the past 20 years owing to their characteristics of being informative, highly polymorphic, multi-allele, co-dominant, experimentally reproducible, and transferable across the species (Vieira et al., 2015). Moreover, the microsatellite is greatly useful in diversity assessment measured in terms of genetic distance, cultivar identification through DNA fingerprinting, linkage and QTL analysis, and even in evolutionary studies (Kalia et al., 2011). In this study, two markers - MillHR28 and MillHR30- 
Table 1. Characterization of 20 polymorphic microsatellite markers based on 116 Mangifera indica accessions.

\begin{tabular}{lccccc}
\hline Marker & $\begin{array}{c}\text { Major Allele } \\
\text { Frequency }\end{array}$ & $\begin{array}{c}\text { Allele } \\
\text { No }\end{array}$ & $\begin{array}{c}\text { Gene } \\
\text { Diversity }\end{array}$ & Heterozygosity & PIC \\
\hline MillHR01 & 0.5690 & 3 & 0.5352 & 0.1078 & 0.4429 \\
MillHR06 & 0.3822 & 9 & 0.6917 & 0.6405 & 0.6310 \\
MillHR07 & 0.5886 & 7 & 0.6033 & 0.5232 & 0.5669 \\
MillHR10 & 0.9959 & 2 & 0.0082 & 0.0000 & 0.0081 \\
MillHR11 & 0.8197 & 4 & 0.2978 & 0.3525 & 0.2570 \\
MillHR12 & 0.6537 & 5 & 0.4917 & 0.4631 & 0.4221 \\
MillHR14 & 0.9044 & 4 & 0.1751 & 0.1644 & 0.1639 \\
MillHR16 & 0.6749 & 5 & 0.4563 & 0.3786 & 0.3759 \\
MillHR18 & 0.3960 & 9 & 0.7535 & 0.3584 & 0.7201 \\
MillHR20 & 0.7889 & 4 & 0.3571 & 0.3238 & 0.3313 \\
MillHR21 & 0.9710 & 2 & 0.0564 & 0.0134 & 0.0548 \\
MillHR22 & 0.5840 & 6 & 0.5908 & 0.0820 & 0.5427 \\
MillHR24 & 0.3642 & 7 & 0.7406 & 0.6207 & 0.7000 \\
MillHR25 & 0.8017 & 2 & 0.3180 & 0.2727 & 0.2674 \\
MillHR26 & 0.6507 & 10 & 0.5488 & 0.4629 & 0.5248 \\
MillHR27 & 0.8598 & 6 & 0.2527 & 0.2218 & 0.2408 \\
MillHR28 & 0.2626 & 11 & 0.8192 & 0.5756 & 0.7953 \\
MillHR29 & 0.2766 & 8 & 0.8017 & 0.8443 & 0.7740 \\
MillHR30 & 0.4144 & 11 & 0.7616 & 0.7658 & 0.7361 \\
MillHR32 & 0.4471 & 7 & 0.6704 & 0.5110 & 0.6140 \\
\hline Mean & 0.6203 & 6.1000 & 0.4965 & 0.3841 & 0.4585 \\
\hline
\end{tabular}

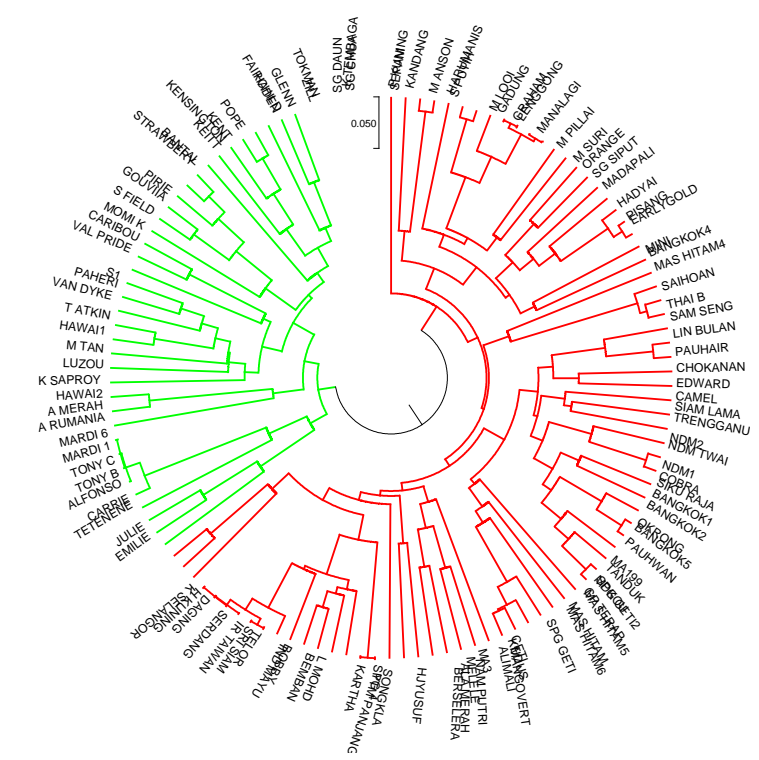

Fig 1. Dendogram based UPGMA approach of 116 mango accessions using 20 polymorphic SSR markers.

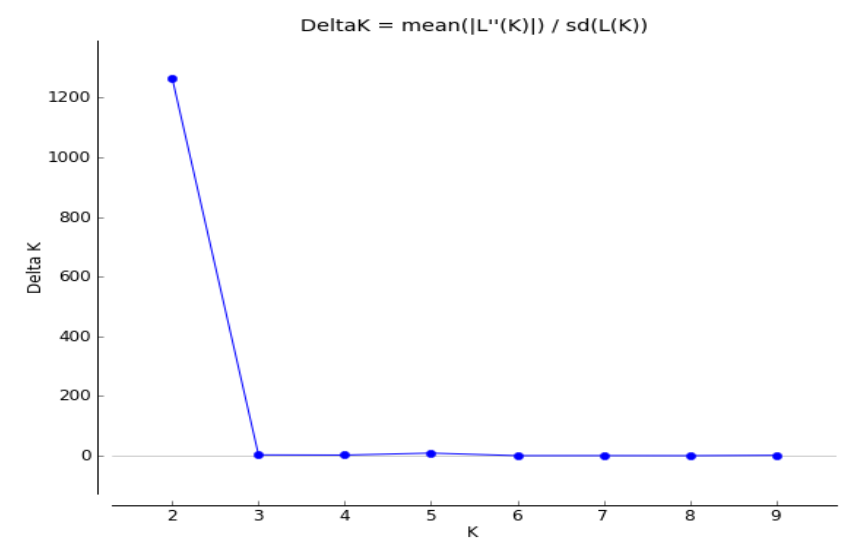

Fig 2. Estimation of number of population structure, $K$ where $K=2$ based on $\Delta K\left(\Delta K=m\left(\left[L^{\prime \prime} K\right]\right) / s[L(K)]\right)$ where the optimal number of $\mathrm{K}$ refers to the highest value of $\Delta \mathrm{K}$. 


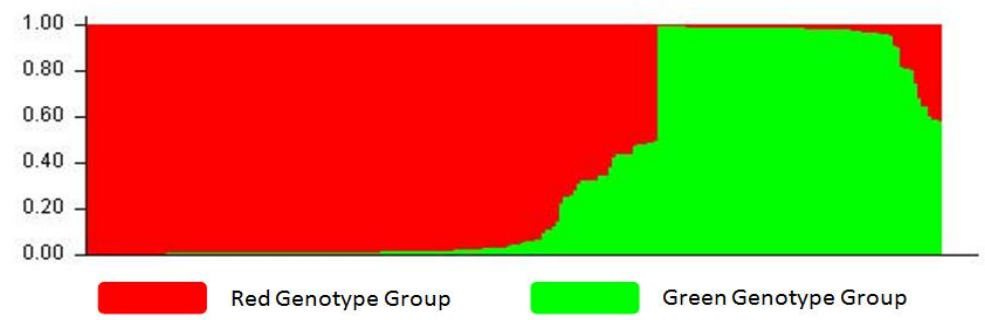

Fig 3. Diagram of population genetic structure generated by Structure program, when $K=2$ as determined by $\Delta K=m\left(\left[L^{\prime \prime} K\right]\right) / s[L(K)]$, based on 20 polymorphic SSR markers. The diagram suggest the presence of two genetically distinct genotype groups among the accessions. Both clusters showed a mixture of poly-embryonic and mono-embryonic seed-type varieties in their cluster.

showed the presence of the highest number of alleles, with 11 alleles each detected for both markers. Both these markers represent the dinucleotide perfect repeat motif microsatellite type, with high numbers of repeat motifs (11 and 12 repeats, respectively). This is in agreement with the study conducted by Merrit et al. (2015), wherein the frequency of repeats were positively correlated with the number of alleles detected, suggesting that longer repetitive sequences tended to have higher chances and greater extent of polymorphism irrespective of the mutation mechanism (Primmer et al., 1996; Ellegren, 2004). Besides, the study by Merrit et al. (2015) also demonstrated that microsatellite markers with dinucleotide repeat motifs showed a significantly higher number of alleles compared to the tri-, tetra-, and penta-nucleotide repeats, which might be caused by the relative ease of mutation via DNA slippage during replication (Chakraborty et al., 1997; Ellegren, 2000). Even though a desired level of polymorphisms was produced, the major drawbacks of dinucleotide repeat motif included difficulty in scoring, as they produced more stutter peaks compared to other repeat motifs (Merrit et al., 2015). Besides, both markers (MillHR28 and MillHR30) also represented perfect repeat motif microsatellite markers, and Merrit et al. (2015) observed that microsatellite markers with perfect motif appeared to produce higher levels of genetic polymorphism (in terms of higher number of alleles) than microsatellite markers with imperfect/interrupted repeat motifs.

The duplication of the accessions is undeniably prevalent in germplasm banks. In addition, the identification of duplicate accessions is important for the reduction of maintenance costs as well as to facilitate appropriate management of germplasm banks. Besides, the identification of duplicate also helps in the genetic breeding program, since the identical genotypes or accessions will then not be chosen for field trial experiments, avoiding crossing between them. The phenomenon of duplication appears to be common in vegetative propagated plants (Irish et al., 2010), owing to regular exchanges of the propagules among farmers of different regions, especially for cultivars having high economical value. When introduced to a new place, the accession/genotypes may receive a new name, resulting in duplication of samples and maintenance of the accessions on the germplasm banks. Thus, although characterization with molecular markers can help identify duplicate, the genetically identical accessions may not be discarded immediately, at least before characterization is complete. This study showed the possibility of occurrence of four duplicate groups with highly similar genotypic data sets within their group (Group 1: Harumanis, MLooi, Gadung, and Graham; Group 2: Berselera and Haji Yusuf; Group 3: Bobby, Ind_Mayu, Telor, Sri Siam, IR Taiwan, and Serdang; Group 4: Tony_B, Tony_C, MARDI_1, and MARDI_6). Characterization based on morphology is still important in the evaluation of all accessions with the purpose of identity confirmation. Similar studies, on hevea (de Souza et al., 2015), cassava (Moura et al., 2013), potato (Favoretto et al., 2011) and Plum (Šiško, 2016), have reported the identification of duplication in germplasm collection through the use of microsatellite markers.

The finding of this study showed both clusters (Green and Red cluster) consisted of a mixture of poly- and monoembryonic seed types. A large number of the accessions are still in the assessment and evaluation stage, which makes it impossible to confirm the seed type contained in each accession. Nevertheless, the commercial mango and some established mangoes were shown to have a mix of the mono-embryonic and poly-embryonic seed type. For example, the variety Kensington pride has poly-embryonic seeds, while Keitt has mono-embryonic seeds, although both varieties are grouped together in the green cluster of the dendrogram. A previous study conducted by Tsai et al. (2013) also could not separate mono-embryonic seedbearing cultivars from poly-embryonic ones despite using 37 microsatellite markers. Besides, the studies by Schnell et al. (1995) and Eiadthong et al. (1999) using the dominant markers RAPD and ISSR, respectively, were also unable to separate the mono-embryonic and poly-embryonic seedbearing cultivars. A recent study by Sherman et al. (2015), using Single Nucleotide Polymorphism (SNP) markers derived from transcriptome sequences, was also unable to distinguish between the mono-embryonic group and the poly-embryonic group. In contrast, Lopez-Valenzuela et al. (1997) were able to separate the two groups using RAPD markers.

Generally, cultivars originating from Southeast Asia, as well as tropical Latin America are poly-embryonic, while those originating from Florida and India are largely monoembryonic (Vasanthaiah et al., 2007). The plants developing from apomictic embryos of poly-embryonic seeds are genetically similar to the maternal plants. This property facilitates easy clonal propagation and also allows the development of cultivars from their own roots. Polyembryony in mango was originally hypothesized to be under the control of recessive genes. However, the subsequent genetic evidence proved that poly-embryony in mango is actually under the control of a single dominant locus. A study conducted by Kuhn et al. (2017) reported a significant 
association between a single locus with the dimorphic seed type (mono-embryonic and poly-embryonic) in Linkage Group 8 (LG8). Their study also suggested that a heterozygous dominant allele regulates polyembryony, while the homozygous recessive allele regulates monoembryony.

\section{Materials and Methods}

\section{Plant material and genomic DNA isolation}

A total of 224 samples representing 116 mango accessions were obtained from the mango germplasm at the Malaysian Agriculture Research and Development Institute (MARDI), Sintok, Malaysia ( $\left.6^{\circ} 28^{\prime} 53^{\prime \prime} \mathrm{N}, 100^{\circ} 29^{\prime} 00^{\prime \prime} \mathrm{E}\right)$. The details of the accessions are summarized in Supplementary Table 1. Young fresh leaves of each individual were collected and stored with silica gel in a zip lock plastic for air drying. Small fragments of the young leaves were transferred onto a 96well plate containing stainless steel beads $(2.3 \mathrm{~mm}$ diameter) and were immediately frozen at $-80^{\circ} \mathrm{C}$ for a minimum of one night. The frozen tissue was ground using Tissue Lyser (Qiagen, Germany) immediately after addition of the Extraction buffer ( $2 \%$ CTAB, pH8 of $100 \mathrm{mM}$ Tris- $\mathrm{HCl}$, $20 \mathrm{mM}$ EDTA, $1.4 \mathrm{M} \mathrm{NaCl}, 0.05 \% \beta$-mercaptoethanol). The total genomic DNA was extracted using the method described by Mace et al. (2003). The integrity of the DNA was estimated on $0.8 \%$ agarose gels, while DNA concentration was measured using Fluoraskan Ascent (Thermo Fisher Scientific, United States).

\section{SSR genotyping}

A total of 32 SSR markers (Supplementary Table 2) were chosen from a previous study by Ravishankar et al. (2011). The PCR was performed as described by Schuelke (2000) by ligating one of the locus-specific primers (either forward or reverse) with a non-fluorescent labeled M13 sequence tail (TGTAAAACGACGGCCAGT) and an M13 adapter labeled with a fluorescent dye (FAM, PET, or VIC). The PCR reaction mixture was prepared to a final volume of $10 \mu \mathrm{L}$, and contained 1x buffer (Invitrogen, United States), $10 \mu \mathrm{M}$ each of forward and reverse primer, $5 \mu \mathrm{M}$ fluorescence-labeled M13 primer, $2 \mu \mathrm{M}$ of each dNTP (Invitrogen, United States), $0.1 \mu \mathrm{L}$ of bovine serum albumin (BSA) as PCR enhancer and 1 $U$ of Taq polymerase (Invitrogen, United States). Amplification was performed using GeneAmp ${ }^{\circ}$ PCR System 9700 (Applied Biosystems, United States) with initial denaturation at $94^{\circ} \mathrm{C}$ for $2 \mathrm{~min}$, followed by 35 cycles of 94 ${ }^{\circ} \mathrm{C}$ for $30 \mathrm{sec}, 41-65{ }^{\circ} \mathrm{C}$ for $45 \mathrm{sec}$, and $72{ }^{\circ} \mathrm{C}$ for $45 \mathrm{sec}$, followed by final extension at $72{ }^{\circ} \mathrm{C}$ for $7 \mathrm{~min}$. After the amplification, the PCR product was multiplexed using up to four primers with a combination of four different fluorescent dyes. The products were then diluted and mixed with Hi-Di formamide and GeneScan 500 LIZ, which were used as standard molecular weight ladder (Applied Biosystems, United States), before being resolved using ABI 3130xL Genetic Analyzer (Applied Biosystems, United States).

\section{Statistical analysis}

The allele-scoring program GeneMapper Version 5 (Thermo Fisher Scientific, United States) was used to score the allele size. The generated electropherograms were scored and analyzed as described by Arif et al. (2010). The software PowerMarker was used to calculate the number of alleles, Major Allele Frequency, Gene Diversity, the extent of heterozygosity, and Polymorphism Information Content (PIC) of each microsatellite marker. The shared-allele genetic-distance base was calculated using PowerMarker software (Liu and Muse, 2005) and was used to describe the genetic relationships among all accessions. In addition, MEGA7 (Kumar et al., 2016) was used to generate dendrogram based on the Unweighted Pair Group Method with Arithmetic Mean (UPGMA) which constructed using the calculated matrices genetic distance of the shared microsatellite alleles. The software STRUCTURE version 2.3 (Pritchard et al., 2000) was used to assign the individuals to their respective cluster based on Bayesian clustering in the absence of knowledge on their population affinity. The number of genotype groups (K) was assessed from one to nine with 20 independent runs per $K$ value, with run length of 100,000 generations as burn-in period and 100,000 Markov chain Monte Carlo (MCMC) repetitions. The optimal value of $K$ was calculated using the value of Delta $K(\Delta K)$, calculated as $\Delta \mathrm{K}=\mathrm{m}\left(\left[\mathrm{L}^{\prime \prime} \mathrm{K}\right]\right) / \mathrm{s}[\mathrm{L}(\mathrm{K})]$ described previously by Evanno et al. (2005) by using STRUCTURE HARVESTER (Earl, 2012).

\section{Conclusion}

Evaluation of the genetic diversity in germplasm is essential and greatly useful in germplasm conservation management. Application of molecular markers has been globally accepted to be an efficient and effective way for management or evaluation of the genetic diversity of the germplasm. Besides, understanding the diversity of the germplasm allows the breeder to exploit the heterosis by crossing diverse accessions. Besides, duplications detected in the germplasm could also prevent the breeder from crossing among the duplicated accessions, avoiding genetic depression which could be caused by inbreeding.

\section{Acknowledgements}

The authors would like to thanks to Malaysian Government for the financial funding under National Key Economic Area (NKEA) - EPP14. Besides, the authors also would like to thanks MARDI staff that directly and indirectly helped in this project. The authors would like to thanks Sci-Edit Publications (http://www.sci-edit.com/) for the English language review.

\section{References}

Arif IA, Khan HA, Shobrak M, Al Homaidan AA, Al Sadoon M, Al Farhan AH, Bahkali AH (2010) Interpretation of electrophoretograms of seven microsatellite loci to determine the genetic diversity of the Arabian Oryx. Genet Mol Res. 9(1): 259-265.

Bhat ZA, Dhillon WS, Rashid R, Bhat JA, Dar WA, Ganaie MY (2010) Role of molecular markers in improvement of fruit crops. Not Sci Biol. 2(2): 22-30. 
Bompard JM (1993) The genus Mangifera re-discovered: the potential contribution of wild species to mango cultivation. Acta Hortic. 341: 69-77.

Chakraborty R, Kimmel M, Stivers DN, Davison L, Deka R (1997) Relative mutation rates at di-, tri-, and tetranucleotide microsatellite loci. Proc Natl Acad Sci U S A. 94(3): 1041-1046.

de Souza, LM, Le Guen V, Cerqueira-Silva CBM, Silva CC, Mantello CC, Conson ARO, Vianna JPG, Zucchi MI, Junior EJS, Fialho JDF, de Moraes MLT, Goncalves PDS, de Souza AP (2015) Genetic diversity strategy for the management and use of rubber genetic resources: more than 1,000 wild and cultivated accessions in a 100-genotype core collection. PloS One. 10(7): e0134607.

Earl DA (2012) STRUCTURE HARVESTER: a website and program for visualizing STRUCTURE output and implementing the Evanno method. Conserv Genet Resour. 4(2): 359-361.

Eiadthong W, Yonemori K, Sugiura A, Utsunomiya N, Subhadrabandhu S (1999) Identification of mango cultivars of Thailand and evaluation of their genetic variation using the amplified fragments by simple sequence repeat-(SSR-) anchored primers. Sci Hort. 82(1-2): 57-66.

Ellegren $\mathrm{H}$ (2000) Heterogeneous mutation processes in human microsatellite DNA sequences. Nature Genet. 24(4): 400-402.

Ellegren H (2004). Microsatellites: simple sequences with complex evolution. Nat Rev Genet. 5(6): 435-445.

Evan EA, Mendoza OJ (2009) World mango trade and the economics of mango production. In: Litz RE (ed) The MangoBotany, Production and Uses, 2nd edn. CAB International, Bodmin. 606-627.

Evanno G, Regnaut S, Goudet J (2005) Detecting the number of clusters of individuals using the software STRUCTURE: a simulation study. Mol Ecol. 14(8): 2611-2620.

Favoretto P, Veasey EA, Melo PCTD (2011) Molecular characterization of potato cultivars using SSR markers. Hortic Bras. 29(4): 542-547.

Hildebrand CE, David C, Torney C, Wagner P (1994) Informativeness of polymorphic DNA markers. In: Cooper NG (ed) The human genome project: deciphering the blueprint of heredity, University Science Books, Sausalito. 100-102.

Irish BM, Goenaga R, Zhang D, Schnell R, Brown JS, Motamayor JC (2010) Microsatellite fingerprinting of the USDA-ARS Tropical Agriculture Research Station cacao (Theobroma cacao L.) germplasm collection. Crop Sci. 50(2): 656-667.

Iyer CPA, Degani C (1997) Classical breeding and genetics. In: Litz RE (ed) The Mango-Botany, Production and Uses. CAB International, Wallingford Oxon, 49-68.

Kalia RK., Rai MK, Kalia S, Singh R, Dhawan AK (2011) Microsatellite markers: an overview of the recent progress in plants. Euphytica. 177(3): 309-334.

Khan AS, Ali S, Khan IA (2015) Morphological and molecular characterization and evaluation of mango germplasm: An overview. Sci Hort. 194(2015): 353-366.

Kuhn DN, Bally IS, Dillon NL, Innes D, Groh AM, Rahaman J, Ophir R, Cohen Y, Sherman A (2017) Genetic map of mango: a tool for mango breeding. Front Plant Sci. 8(577): 1-11.

Kumar S, Stecher G, Tamura K (2016) MEGA7: molecular evolutionary genetics analysis version 7.0 for bigger datasets. Mol Bio Evol. 33(7): 1870-1874.

Litz RE (2004) Biotechnology and mango improvement. Acta Hortic. 645, 85-92.

Liu K, Muse SV (2005) PowerMarker: an integrated analysis environment for genetic marker analysis. Bioinformatics. 21(9): 2128-2129.

Lopez-Valenzuela JA, Martinez O, Paredes-Lopez O (1997) Geographic differentiation and embryo type identification in Mangifera indica L. cultivars using RAPD markers. HortScience. 32(6): 1105-1108.
Luo $\mathrm{C}$, He XH, Chen H, Ou SJ, Gao MP, Brown JS, Tondo CT, Schnell RJ (2011) Genetic diversity of mango cultivars estimated using SCOT and ISSR markers. Biochem Syst Ecol. 39(4-6): 676-684.

Mace ES, Buhariwalla KK, Buhariwalla HK, Crouch JH (2003) A high-throughput DNA extraction protocol for tropical molecular breeding programs. Plant Mol Biol Report. 21(4): 459-460.

Majumder DAN, Hassan L, Rahim MA, Kabir MA (2012) Analysis of genetic diversity in mango (Mangifera indica L.) using isozymetic polymorphism. Afr J Biotechnol.11(87): 1531015323.

Merritt BJ, Culley TM, Avanesyan A, Stokes R, Brzyski J (2015) An empirical review: Characteristics of plant microsatellite markers that confer higher levels of genetic variation. Appl Plant Sci. 3(8): 1500025.

Moura EF, Farias Neto JTD, Sampaio JE, Silva DTD, Ramalho GF (2013) Identification of duplicates of cassava accessions sampled on the North Region of Brazil using microsatellite markers. Acta Amazon. 43(4): 461-467.

Primmer CR, Ellegren H, Saino N, Møller AP (1996) Directional evolution in germline microsatellite mutations. Nature Genet. 13(4): 391-393.

Pritchard JK, Stephens M, Donnelly P (2000) Inference of population structure using multilocus genotype data. Genetics. 155(2): 945-959.

Pruthvish R, Chikkaswamy BK (2016) Genetic Diversity and Relationships among Mango Varieties using RAPD Molecular Markers. Int J Curr Microbiol App Sci. 5(1): 778-787.

Ravishankar KV, Mani BHR, Anand L, Dinesh MR (2011) Development of new microsatellite markers from Mango (Mangifera indica) and cross-species amplification. Am J Bot. 98(4): e96-e99.

Shamili M, Fatahi R, Hormaza JI (2012) Characterization and evaluation of genetic diversity of Iranian mango (Mangifera indica L., Anacardiaceae) genotypes using microsatellites. Sci Hort. 148(2012): 230-234.

Schnell RJ, Ronning CM, Knight RJ (1995) Identification of cultivars and validation of genetic relationships in Mangifera indica L. using RAPD markers. Theor Appl Genet. 90(2): 269274.

Schuelke M (2000) An economic method for the fluorescent labeling of PCR fragments. Nature Biotechnol. 18(2): 233-234.

Sherman A, Rubinstein $M$, Eshed $R$, Benita $M$, Ish-Shalom $M$, Sharabi-Schwager M, Rozen A, Saada D, Cohen Y, Ophir R (2015) Mango (Mangifera indica L.) germplasm diversity based on single nucleotide polymorphisms derived from the transcriptome. BMC Plant Biol. 15(277): 1-11.

Šiško M (2016) Identification of hypothetical duplicate accessions of plums (Prunus domestica L.) within the slovene plant gene bank collection using molecular markers. Agricultura. 13(1-2): 57-64.

Tsai CC, Chen YKH, Chen CH, Weng IS, Tsai CM, Lee SR, Lin YS, Chiang YC (2013) Cultivar identification and genetic relationship of mango (Mangifera indica) in Taiwan using 37 SSR markers. Sci Hort. 164(2013): 196-201.

Vasanthaiah HKN, Ravishankar KV, Mukunda GK, (2007) Mango. In: Kole C (ed) Genome Mapping and Molecular Breeding in Plants. Fruits and Nuts, vol. 4. Springer-Verlag, Berlin Heidelberg. 303-323.

Vieira MLC, Santini L, Diniz AL, Munhoz CDF (2016) Microsatellite markers: what they mean and why they are so useful. Genet Mol Biol. 39(3): 312-328. 